\title{
LEITOR GERAL ESCLARECIDO, SUA FORMAÇÃO HISTÓRICA E SUA RECEPÇÁOO DE POESIA
}

\author{
Jamesson Buarque de Souza*
}

\begin{abstract}
Resumo
Neste artigo, apresentamos um brevíssimo histórico sobre a formação do leitor geral brasileiro, de acordo com princípios teóricos da Estética da Recepção. Tal histórico nos serviu para a descrição do conceito de leitor geral esclarecido, o qual cunhamos convergindo a apreciação historiográfica à semiótica da recepção. O resultado foi, imbricado na descrição desse tipo de leitor, a proposiçáo de um modelo de desenvolvimento de sua recepçáo estética, a fim de chamar a atenção da comunidade acadêmica para que um modelo de leitura de poesia somente é viável mediante a tomada de consciência da formação histórica e do contexto sócio-histórico do leitor.
\end{abstract}

PalaVras-Chave:Leitor geral esclarecido, recepção estética, leitura de poesia.

\section{General aware reader, its historic formation and poetry reception}

\section{Abstract}

In this paper we present a brief account of the formation of Brazilian general reader, in accordance with theoretical principles by Aesthetic of Reception. This brief account was useful to describe the concept that we called general aware reader, converging historiographic appreciation to semiotics reception. The result was, imbricated in the description of this kind of reader, the proposition of a model of development in Aesthetic Reception so as to call attention of the academic community to understand that a model of poetry reading is only viable by means of an awareness of the historical formation and the socio-historical context of the reader.

KEY WORDS: general aware reader, aesthetic reception, reading of poetry.

Este artigo descreve e argumenta sobre o leitor geral esclarecido, conceito nosso, o qual corresponde a uma instância do leitor de poesia. Para tanto, fizemos uma apreciação crítico-descritiva sobre os resultados de investigação historiográfica de José Veríssimo (1976), Nelson Werneck Sodré (1995), Mariza Lajolo e Regina Zilberman (1996), Jorge Araujo (1999) e Antonio Candido (2000). Dessa apreciação, formulamos um brevíssimo

Professor da Universidade Federal Rural de Pernambuco. Doutor em Estudos Literários pela UFG. E-mail: jamessonbuarque@gmail.com. 


\section{Revista Solta a Voz, v. 19, n. 1}

histórico da formação do leitor brasileiro, que, abordado a partir da semiótica da recepção, de Umberto Eco (1995), e de princípio teóricos da Estética da Recepção (Iser, 1979, 1999; Jauss, 1979; Stierle, 1979), conduziu-nos a uma descrição do leitor geral esclarecido, na qual deixamos incluso um modelo de desenvolvimento de sua capacidade de leitura.

A relação do leitor geral brasileiro com a poesia nos remete ao nascimento da escritura literária no Brasil. Esse nascimento é bem estranho, porque vige no período em que, na entâo Colônia, não havia expectativa de leitura. Podemos dizer que isso ocorria porque a colonização portuguesa na América jamais se efetivou pelo intercâmbio de produção literária, filosófica ou outra de natureza intelectual. Sobre isso, Jorge Araujo (1999, p. 20) diz que "a experiência colonizadora portuguesa em muito diferiu da espanhola [...]. Os espanhóis trouxeram livros em suas aventuras de anexação de territórios". Logo, Portugal não trouxe livros que pudessem estimular, já de princípio, uma cultura literária, ou um imaginário fictício na terra colonizada ou algum modo de intectualidade. Fosse pelo imaginário que povoava as crônicas coloniais do século XVI na América lusitana, fosse pela lírica catequética de Anchieta ou por seu encômio épico De gestis Mendi de Saa, fosse pelo poema Prosopopéia de Bento Teixeira, a escritura literária na Colônia não preconcebia recepção local. Durante muito tempo, no cenário colonial da época não havia público, nem crítica especializada e nem um conjunto de outros escritores. É importante frisar que não houve, antes do século XIX, nenhuma política para a propagação da leitura no Brasil — como também diz Araujo (1999, p. 20):

Portugal influiu aqui pela negação da cultura de livros, uma vez que, com exceção do século XIX, a partir da mudança da Corte para o Brasil, nunca houve real decisão política de tráfego de livros, mesmo os de cavalaria, para cá. Certo que o século XVIII, com o modelo da ilustraçáo pombalina, desenvolveu e intensificou aqui uma certa pedagogia de época, com os previsíveis desdobramentos quanto aos interesses do colono no campo de uma bibliografia específica. Mas é o século XVIII que também proíbe a Antonio Isidoro da Fonseca de aqui instalar-se com sua editora e sua experiência de impressor.

Os primeiros escassos letrados da Colônia tiveram suas preocupações voltadas para as possibilidades econômicas da terra. No que se trata de livro, principalmente literário, pouco havia. Quase tudo desse pouco previa 
recepção de cunho catequético. À parte disso, havia também a pertinência do ideal de heroificação do tipo português próximo à (senão da) nobreza ou fidalguia, bem como da propagaçáo do ideal cristão pelo catolicismo jesuíta. Mas um ideal ou outro não se afasta do centro de possibilidades econômicas da terra, porque heroificação e catequismo tendem a conduzir a uma consciência histórica que supervaloriza a presença do grupo de poder, para o atenuamento dos malefícios de suas exploraçóes mercantis. A primeira expressão (mercantilismo) foi marcada pela crônica dos viajantes; a segunda e a terceira (heroificação e catequismo), tanto pela épica quanto pela lírica. Sobre isso é importante alguns resultados da historiografia de Nelson Werneck Sodré (1995, p. 49-73). Ali ele trata da sociedade brasileira, observando a origem social dos colonizadores e a presença jesuítica. Aproveitamos para notificar que a "deficiência" na formação do leitor brasileiro se deve em muito a esse gérmen de degredo social que Portugal fomentou no Brasil desde os primeiros anos de colonização.

Araujo (1999, p. 26-27) também diz que a Colônia não chegou a conhecer a produção de seus cronistas. Havia a produção sobre a Colônia, mas não para a Colônia. Quanto ao texto teatral, apenas indiretamente é que foi especulado no Brasil: o contato se dava apenas para a representação de ordem catequética. De certo modo, as primeiras manifestaçôes literárias na terra nova é literatura para quase ninguém, uma vez que tais manifestaçóes previam a nobreza e a fidalguia não residentes na Colônia, porque, quando do achamento, ninguém dessa natureza se afigurou. Como afirma Sodré (1995, p. 49): "Os elementos humanos que chegam às zonas coloniais não têm outra finalidade senão produzir em larga escala, para abastecer mercados distantes". Tais "elementos" não eram de origem nobre, porque os desta origem não se lançavam à aventura ultramarina como aventureiros, que não tendo nada a perder, arriscam, pelo menos, plantar seu nome na história. O que de literatura isso pode motivar foi um ideal heróico para retrato dos feitores. Aqueles "elementos" não eram dados às letras. Além da atitude de ocupar a terra achada para produzir, o grosso de quem se dava a empreitadas ultramarinas objetivava a conquista de riquezas "fáceis", como as do mito de Eldorado. Portanto, não havia propagações de recepção ou de produção literária. Não havia por parte de Portugal fomento literário para o desenvolvimento humano na fundaçáo de civilizaçôes novas. Ninguém dado à leitura de literatura, ou qualquer leva de colonos que tenham origens em classes sociais mais abastadas - até 
então as únicas "aptas" à recepção de manifestações literárias escritas -, bem como alguém que de algum modo apresentasse histórico de recepção estética, não se lançou na "empresa" de vir à terra achada para o cultivo do pensamento, ciência ou literatura, como também para a recepção disso. Quando se refere a essa época, José Veríssimo (1976) trata sobre esse caráter boçal daqueles que "de fato" colonizaram o Brasil.

O que de/e sobre literatura circulava em Portugal não circulava entre os escassos elementos letrados da Colônia. Náo havia circulaçáo da literatura de cavalaria, nem dos cordelistas e nem de Epicuro, Aristóteles, Sêneca, Cícero, nem D. Dinis e nem D. Afonso X, O Sábio. Mesmo a tradição oral, que tem no repente nordestino sua principal sede, e que apresenta seus primeiros dados com Gregório de Matos Guerra e o Pe. Domingos Caldas Barbosa, os quais improvisavam versos na viola pelo século XVII, não apresentou larga recepção estética, principalmente porque nunca houve uma política estabelecida para o registro impresso dessa tradição. Uma vez que muitos dos cantadores não eram alfabetizados, cabia à Metrópole atitude dessa natureza, como um corpo de copistas. Segundo Mariza Lajolo e Regina Zilberman (1996, p. 18):

Só por volta de 1840 o Brasil do Rio de Janeiro, sede da monarquia, passa a exibir alguns dos traços necessários para a formação e fortalecimento de uma sociedade leitora: estavam presentes os mecanismos mínimos para produção e circulação da literatura, como tipografias, livrarias e bibliotecas; a escolarização era precária, mas manifestava-se o movimento visando à melhoria do sistema; o capitalismo ensaiava seus primeiros passos graças à expansão da cafeicultura e dos interesses econômicos britânicos, que queriam um mercado cativo, mas em constante progresso.

Interpretamos, a partir disso, que até o século XVIII, e, conforme a citação acima, até quase meados do XIX, há densa treva de recepção estética por ação do infeliz programa civilizatório da Metrópole. A respeito desse tópico, Araujo (1999, p. 29) diz que "a Carta de Caminha só veio a ter divulgação dois séculos depois de escrita e enviada". Observe-se também, que, somente em fins do século XVI e início do XVII, "Virgílio, Cícero, Horácio, Ovídio e Sêneca seriam [...] integrados às estruturas curriculares obrigatórias do ensino jesuítico e, em seguida, do experimento pombalino" (Araujo, 1999, p. 35). Ainda nesse ponto, Araujo (1999) comenta que os textos dos latinos vieram adulterados e que Platão e Aristóteles também fo- 
ram introduzidos, mas não poderiam ser lidos no original; e não poderiam não só porque era proibido, mas também pela ausência de conhecimento do grego clássico por parte dos escassos residentes letrados da Colônia. Tais dados deixam em evidência que a expectativa de efeito estético para recepção local passou a ocorrer apenas a partir do século XVIII. Isso se deu com a formação, ainda que deficiente e fadada ao fracasso, das agremiaçôes árcades. Porém, uma justiça precisa ser feita: com Gregório de Matos Guerra, notamos - especificamente em sua fase popular - um caráter peculiar da formação do leitor brasileiro: a tradição oral. Embora esse tipo de tradição não preveja um público leitor, ela prevê uma audiência que, no curso das literaturas, é o nascedouro do público leitor. Consta que, nesse período, já havia na Colônia, ainda que de maneira muito limitada e restrita, a prática de recitais públicos e familiares -, embora não como o quis o sociólogo Bento Teixeira Pinto, que tentou impingir à história da literatura no Brasil o pseudo-fato de que aquela prática era freqüente.

Até antes das agremiaçóes árcades, o que havia de leitor formava um público geral de recepção de boca em ouvido. Esse suposto público era formado de ouvinte "semiósico", ou "semântico", de leitura via de regra "ingênua” (Eco, 1995), quer dizer, de interpretação jamais crítica do material literário. Durante o século XVIII, os escritores pretendiam ser visualmente lidos pelo público: pretendiam ser lidos por leitores de livro em punho. No entanto, quase todo o povo era analfabeto. A educaçáo jesuítica era para poucos e ainda sua concepção humanista, conforme já sabemos, conservava antes intenção catequética do que cultural. Aliás, o que havia de cultural naquela educação era antes individual do que coletivo. Segundo Antonio Cândido (2000), os árcades organizaram academias de leitura, mas terminaram por sortir um efeito estéril no processo receptivo, uma vez que eles eram lidos apenas por eles mesmos. Por isso as agremiaçóes formaram uma tentativa deficiente e fracassada. Da intenção educativa dos árcades, quanto a formarem público leitor de livro em punho, há registros de alguns resultados positivos, como a formação de novos escritores e a conscientização sociopolítica de alguns "elementos" marginalizados pela sociedade da época. Sobre isso, observe-se:

Esta união da literatura à política permitiu o primeiro contacto vivo do escritor com os leitores e auditores potenciais; e nada exprime melhor a ardente fé nas luzes do que os cursos organizados na prisão pelos revolucioná- 
rios de 1817 [...] Muniz Tavares ensinava lógica; frei Caneca, português; Basílio Torreão, geografia e história; Antônio Carlos, inglês... Futuros revoltosos de 1824, como Tristão de Alencar Araripe, aí se aperfeiçoaram e ganharam novas razóes para lutar. (Candido, 2000, p. 79, grifo do autor)

A partir do século XIX, com a vinda da família real e adidos, com a implantação da Imprensa Nacional, o desenvolvimento do romantismo, a política de identidade nacional, o advento do Império, a sobrepujança do realismo, a presença do simbolismo e das universidades, um novo público leitor se formou na ex-colônia, público este diferente do geral e daquele de escritores. Um público formado pelo aristocrata decadente e pelo burguês em ascensão, que lia como pretendiam serem lidos os árcades, mas era formado por poucos "elementos". Lia de livro em punho. No entanto, sua recepção estética não se dava, via de regra, diferentemente do público geral, que lia de ouvido. Quer dizer, era efetivada também em uma relação de prazer e catarse. Lia como aquele outro público ouvia: por entretenimento, pelo riso fácil, pela identidade de si ou do outro com uma personagem de um romance de folhetim. Esse momento, etapa de fruição, é pertinente para formar a etapa de crítica, da vontade de interagir dialética ou elogiosamente com a escritura literária. Eram comuns atitudes como a de rir inconscientemente da própria desgraça, como é a prática, hoje em dia, do telespectador brasileiro em geral. Isso não porque aquele leitor e este telespectador "tiram partido", quer dizer, agem ironicamente mediante o que lêem/assistem, mas porque não atentam para que é de sua própria desgraça que a matéria cômica trata. Se tal leitor e tal espectador fossem críticos, eles perceberiam quais elementos os levavam ao riso. Se haveria riso nessas condiçóes, é o que se busca descobrir em um processo de formação de leitor crítico.

É relevante, neste brevíssimo histórico de formação do leitor brasileiro, a presença do escritor junto ao leitor, quando ambos passaram a configurar-se como "elementos" da e para a Colônia e não apenas na Colônia. Lia-se (ou ouvia-se), pouco, mas se lia (se ouvia). Quando tal configuração tomou vigência, entre outros fatores, a recepçáo estética do período da Colônia até a República Velha tinha no Estado um mecenas do escritor. Se o público não tinha como "manter" o escritor, o Estado o fazia. No entanto, para ser lido, o escritor, via de regra, mantinha o "gosto público" e quase que somente por esse era volvido. Contudo, com a República Nova, o mecenato ou apadrinhamento do Estado para com o escritor foi encerrado. 
Observe-se, no entanto, que em nenhum dos períodos o Estado se preocupou com a formação de público leitor. Logo, toma-nos de assalto Octavio Paz (1976, p. 96) ao dizer: "Uma poesia sem sociedade seria um poema sem autor, sem leitor e, a rigor, sem palavras. Condenados a um perpétua conjunção que se resolve em instantânea discórdia, os dois termos buscam uma conversação mútua”. Assim, da cisão entre escritor e público, temos que, dentre outros fatores, os românticos, realistas, naturalistas e os parnasianos tardios eram as vitrines das atençóes até a década de 1930, ao passo que os modernistas eram marginalizados, uma vez que esses estavam fora do contrato de mecenato do Estado. Somente depois do rompimento com esse contrato é que o modernista passa a ser recebido de acordo com a convergência do discurso de sua escritura em relação aos componentes de identidade nacional, por exemplo, reconhecidos pelo público leitor em um dado poema.

No mais, novamente Octavio Paz (1976, p. 96) nos move a pôr em cena que

[a] idéia cardeal do movimento da era moderna é a criação de uma sociedade universal que, ao abolir as opressóes, desenvolva simultaneamente a identidade ou semelhança original de todos os homens e a radical diferença ou singularidade de cada um.

Podemos dizer que, por isso, a partir da década de 1930, com o Estado Novo, o quadro se inverte, na medida de nosso comentário final no parágrafo anterior. Mas também, por outro lado, uma vez encerrado aquele mecenato e por isso findo o compromisso com o "gosto público" e com os moldes classicistas, o escritor rompe seu contrato com o público. Esse fato também decorre de este não ter como "manter" aquele, devido à má distribuição de renda e ao elitismo da educação literária, ainda vigentes no Brasil. O modernismo começou a afirmar-se, mas "mudou a idéia que o homem fazia de si mesmo: não obstante, os mundos não deixaram de ser o mundo nem o homem os homens. [...] Agora o espaço se desagrega e se expande; o tempo se torna descontínuo" (Paz, 1976, p. 101). Assim é que a literatura moderna chegou como literatura fragmentada, literatura de um mundo em pedaços. O compromisso do escritor passou a ser com suas concepçóes estéticas, que ele forma avultando-as muitas vezes hermeticamente, e conforme não houve, nem havia, nem há política efetiva de formaçáo de público leitor no Brasil - sobretudo de poesia -, essa 


\section{Revista Solta a Voz, v. 19, n. 1}

produção estética é de pouca acessibilidade de apreensão - e até mesmo de aproximaçáo - por um possível público de senso crítico.

Sem uma história de formaçáo propícia de sociedade leitora, sem os moldes estruturais dos classicismos, como regras de composição que serviam de norte à recepção estética, fica difícil vislumbrar um público leitor de senso crítico no Brasil. Ademais, com escritores cada vez mais volvidos a seu projeto estético particular, depois da descoberta do inconsciente por Freud, da fundamentação do relativismo por Einstein, bem como depois das vanguardas, dos modernismos em geral, da crise das metanarrativas e da Segunda Guerra (que vem gerando a tentativa de diálogo, ainda que comercial, entre as mais díspares culturas do planeta), fica difícil prever aquele tipo de público sem proporcionar exaustivo contato com a escritura literária. Fica difícil sobretudo no Brasil, país cujo acesso aos requintes do livro está limitado a 14\% da população, quer dizer, ao nicho mais sócioeconomicamente bem situado da classe média e às classes média-alta e alta, que têm acesso a TV à cabo e à Internet de banda larga em domicílio, bem como assinam (ou compram em banca) pelo menos um grande jornal e uma grande revista de política, sociedade e cultura dentre o todo que circula nacionalmente.

Em linhas gerais, cada vez mais, resta, no Brasil da década de 1930 até esta primeira década do século XXI: um público geral que basicamente deixa de ser leitor, porque, para efetivar a relação de prazer e catarse o material literário é facilmente substituído pelos multimeios de massa. Em outras palavras, como bem observa Candido (2000, p. 85, grifo do autor):

Com efeito, o escritor se habituou a produzir para públicos simpáticos, mas restritos, e a contar com a aprovaçáo dos grupos dirigentes, igualmente reduzidos. Ora, esta circunstância, ligada à esmagadora maioria de iletrados que ainda hoje caracteriza o país, nunca lhe permitiu diálogo efetivo com a massa, ou com um público de leitores suficientemente vasto para substituir o apoio e o estímulo de pequenas elites.

$\mathrm{O}$ que resta como leitores de fato: um público de leitores-escritores, que, de certo modo, mantém a esterilidade da recepção; um público de críticos, que desde meados do século XIX vem se formando para o exercício profissional da recepção estética, e um público que, deste ponto em diante, chamamos de acadêmico, o qual se encontra em formação, mas que se compóe de "elementos" esporádicos, porque são suscetíveis aos multimeios. Dentro deste último público está o que chamamos de leitor geral esclarecido. 
Um problema pertinente é se o leitor geral esclarecido é emancipado ou apto a uma emancipação. Tal problema advém de esse leitor viver submisso a um interesse arbitrário e não-seu. Lajolo e Zilberman (1996) nos aguçam para esse problema, debruçadas sobre "práticas culturais e econômicas" que envolvem "a formação da leitura no Brasil". O problema persiste porque se faz literatura no Brasil para poucos, ou são confeccionados livros didáticos que abordam poesia ou antologias em que os poemas estáo impressos como pílulas anti-histamínicas: tudo é fragmento para um bem-estar respiratório momentâneo. Quanto ao leitor estar apto a emancipar-se, julgamos que este estudo é um passo, pelo menos para o leitorgeral esclarecido. Assim julgamos que nossas consideraçôes críticas - teoricamente fundamentadas nos princípios da Estética da Recepção da Escola de Constanz (Iser, 1979, p. 83-132, 1999, p. 21-33; Jauss, 1979, p. 43-61; Stierle, 1979, p. 133-197) - ao apreciarem, em síntese, nos estudos detalhados dos autores citados, a história da formação do leitor brasileiro, promove um alerta para a comunidade acadêmica interessada. Nosso alerta assevera que não devemos pensar em programas de formaçáo de leitores de poesia apenas a partir de modelos de recepção, mas sobretudo a partir da consciência do cenário sócio-histórico de leitor que temos. Isso porque não podemos apagar o passado, assim como não podemos começar um programa de leitura como se nada tivesse acontecido.

Para complementar nossas considerações críticas e para descrever os dados finais de nossos resultados de investigação, resta responder quem é o leitor crítico esclarecido, quer dizer, o que ele é especificamente. Para tanto, vamos considerar as seguintes palavras de Umberto Eco (1995, p. 1):

[...] do início dos anos sessenta em diante, multiplicam-se [...] as teorias sobre o par Leitor-Autor, e hoje temos [...] leitores virtuais, leitores ideais, leitores-modelo, superleitores, leitores projetados, leitores informados, arquileitores, leitores implícitos, metaleitores.

Esse rol de leitores considera sua "intenção e estatuto: compreensão, atualização e interpretação" (Eco, 1995, p. 1). Considere-se "intenção" por Husserl (1996, p. 31):

dar expressão a atos de toda espécie - representações, juízos, suposições, perguntas, desejos etc. - e, ao fazermos isto eles nos fornecem as significaçôes das respectivas formas da fala, dos nomes, dos enunciados, das proposiçôes interrogativas, optativas etc. 


\section{Revista Solta a Voz, v. 19, n. 1}

O leitor geral esclarecido, instância do leitor acadêmico, converge, em vários aspectos, ainda que de maneira limitada, para muitos desses leitores listados acima. Não nos cabe aqui, nem é nosso propósito, descrever cada um. Convidados a conhecer o trabalho de Umberto Eco acerca da recepçáo estética, será possível reconhecer em nossa descrição aquilo que converge a cada leitor acima. De todo modo, o que mais nos importa é a descrição em-si do leitor geral esclarecido, para que a partir dele possamos tomar consciência de que tipo de leitor forma a massa ínfima de leitores de poesia no Brasil de hoje. De posse desse conhecimento/consciência, é possível propor ou montar um modelo de recepção estética viável a nosso contexto sócio-histórico — jamais no sentido de dar a mão à palmatória, mas no sentido de ter conhecimento de causa para uma ação passível de sucesso.

$\mathrm{O}$ leitor geral esclarecido corresponde a alguns professores, alunos e afins, mas especificamente do curso de Letras e outros das Humanidades. Também boa parte da massa docente de Língua Portuguesa, Língua estrangeira moderna, Literatura Brasileira e Portuguesa, Redação, História, Geografia, Sociologia e Filosofia do Ensino Médio está inclusa nessa instância de leitor. Podemos também incluir, ainda que de maneira mais ínfima, parte da massa discente deste mesmo ensino, levando em conta que estáo em "preparação" para o ingresso na universidade, e esta preparação prevê leitura, ainda que adestrada, de poesia. O leitor geral esclarecido se distingue do leitor crítico especializado, o qual pertence ao mesmo universo do leitor acadêmico. Distingue-se porque aquele pode se dispersar de atitudes conscientes ou sistemáticas de recepção, enquanto a este isso seria romper com sua própria condição de especialista. O leitor geral esclarecido exerce a leitura de poesia com interesse fruitivo, cognitivo e pragmático de sua vida pessoal, muitas vezes à parte de sua vida estudantil e/ou profissional. Todo esse conjunto de observaçóes forma o principal quadro característico desse tipo de leitor. $\mathrm{O}$ fundamental para essa descrição é que esse leitor apresenta conhecimento prévio (sempre) em formação para leitura de poesia. Desse conhecimento, embora sobre a literatura em geral e sobre os leitores anteriormente listados, Umberto Eco (1995, p. 6-7) destaca os seguintes pontos:

Se nos últimos tempos o privilégio conferido à iniciativa do leitor (como único critério de definição do texto) adquire excepcionais características de visibilidade, na verdade o debate clássico articulava-se, antes de mais nada, em torno da oposição entre estes dois programas: 
a) deve-se buscar no texto aquilo que o autor queria dizer;

b) deve-se buscar no texto aquilo que ele diz, independentemente das intençôes do autor.

Só com a aceitação da segunda ponta da oposição é que se poderia, em seguida, articular a oposição entre:

$\left(b_{1}\right)$ é preciso buscar no texto aquilo que ele diz relativamente à sua própria coerência contextual e à situação dos sistemas de significação em que se respalda;

$\left(b_{2}\right)$ é preciso buscar no texto aquilo que o destinatário aí encontra relativamente a seus próprios sistemas de significação e/ou relativamente a seus próprios desejos, pulsóes, arbítrios.

Conquanto, como o semiólogo considera, embora $\left(b_{1}\right)$ e $\left(b_{2}\right)$ sejam relevantes, a "geratividade do texto" e o "enfoque interpretativo" (Eco, 1995, p. 7) é que devem ser o centro da questão que diz respeito ao leitor. Acreditamos nisso principalmente porque, tomando $\left(b_{1}\right)$, cairíamos na metodologia estruturalista desenvolvida principalmente nas décadas de 1960 e 1970. E, tomando $\left(b_{2}\right)$, permitiríamos ao leitor muito mais uma possibilidade de uso do que de interpretação. Umberto Eco (1986, p. 43-44) descreve essa diferenciação expondo principalmente que o "uso" diz respeito à ampliação do universo enciclopédico de um texto, isto é, da possibilidade de a leitura de um texto gerar outro texto que toma um juízo distinto do texto gerador, mas uma realidade estética similar. Enquanto a "interpretaçáo" procura atender ao universo enciclopédico do texto recepcionado, que mesmo paciente de um amplo bojo de inferências, não é paciente de uma inferência qualquer, quer dizer, tem sua enciclopédia limitada. Já o "uso", ao ampliar a enciclopédia do texto, não só cria uma nova como também infringe os limites da primeira. Nada impede o uso nem ele deve ser punido. No entanto, singrá-lo na leitura de poesia seria transformar o objeto de leitura em pretexto para outra coisa, como por exemplo o reconhecimento de um discurso ideológico qualquer, independentemente dos efeitos estéticos. Um poema é, antes de tudo, um texto estético, um objeto artístico.

O leitor geral esclarecido é informado, quer dizer, ele recebeu determinados dados vinculados à arte literária, como: aspectos gramaticais; tipos de discursos; versificação; elementos narrativos; dados políticos, his- 


\section{Revista Solta a Voz, v. 19, n. 1}

tóricos e sociais da nação e do mundo, entre outros. Ele tem um horizonte de recepçáo, pelo menos sumariamente, apto à recepçáo de poesia, porque sabe de algum modo sobre versificação e imagens sob metáforas, assim como porque tem "gosto" voltado para a leitura de poemas - ainda que acesse elementos poéticos via canção. Podemos assumir que esse leitor é capaz de expressar uma interpretação, muito embora esta seja "ingênua" - seja porque náo compreende a obra para interpretá-la, seja porque confunde compreensão com interpretação, seja porque não reflete a obra ou até mesmo porque acredita que interpretar seja refletir.

Em síntese, entenda-se compreensão pelo reconhecimento dos componentes de organização de um poema; reflexão pelo pensar que consegue convergir um sentido a certo componente de organização; e interpretar pelo juízo crítico inferido da reflexão. Em síntese, seria ler este verso de Fernando Pessoa, "e comecei a morrer muito antes de ter vivido", da seguinte maneira: 1) compreensão - o verso coaduna duas unidades heptassilábicas (e comecei a morrer/ muito antes de ter vivido) e implica uma adversidade entre "comecei a morrer" e "antes de ter vivido"; 2) reflexão - o verso nos leva a pensar em contrariedade, porque as unidades coadunadas se opóem mutuamente, logo, a reflexão conduz a uma justificativa mediante o que se compreendeu da expressão do verso; e 3) interpretação - mediante a reflexão, entre outras possibilidades possíveis, o verso nos leva à inferência de que o sujeito do poema está ou é desiludido com as nuanças ou os fatos da vida. É importante observar que essa inferência, embora possa ser paralela a outras, não permite acordar com uma que diga que o sujeito do poema está ou é jubiloso com as nuanças ou os fatos da vida.

O leitor geral esclarecido é, também, "semiósico". Esse adjetivo é descrito por Umberto Eco (1995, p. 12) do seguinte modo:

A interpretação semântica ou semiósica é o resultado do processo pelo qual o destinatário, diante da manifestaçáo linear do texto, preenche-a de significado. [...] Um texto pode ser interpretado tanto semântica como criticamente, mas apenas alguns textos (em geral os de função estética) prevêem ambos os tipos de interpretação. Se digo $O$ gato está em cima do tapete a quem me pergunta onde está o gato, prevejo somente uma interpretação semântica. Se quem diz é Searle, que quer chamar a atenção para a natureza ambígua daquele enunciado, ele prevê também uma interpretação crítica. 
Por isso asseveramos que tal leitor é "semiósico (semântico)", o que a semiologia de Umberto Eco também considera como "leitor-modelo ingênuo". Isso concerne àquele tipo de leitor que foi previsto, por exemplo, por certo poema, mas que não consegue vencer a estratégia de recepçáo do mesmo, devido a precipitaçôes, como já citamos: confundir compreensão com interpretação ou acreditar que refletir sobre um poema, ou de certo segmento dele, é o mesmo que interpretá-lo. Se um sistema de educação, conforme julgamos que deve, julga que precisa potencializar a recepçáo desse leitor, cabe à pedagogia desse sistema tomar consciência da formação histórica desse leitor, de seu cenário sócio-histórico, sobretudo em decorrência da ascensão dos programas de leitura do tipo $\left(b_{1}\right)$ e $\left(b_{2}\right)$, descritos por Umberto Eco. Politicamente processado assim, tal sistema poderá formar leitores e "elevar" o leitor geral esclarecido para a condição de leitor crítico ("semiótico"). Embora isso pareça uma proposta romântica, porque é o mesmo que sugerir a transformação de toda massa de leitores ingênuos em leitores críticos, essa proposta tem um fim bem pragmático: permite que muitos saiam da condição de não-leitores para leitores de poesia, bem como permite que a demanda de leitores críticos se torne mais extensa. Politicamente o resultado disso gera indivíduos menos adestráveis, menos mansos, assim como a nação passa a formar inteligência nativa que atue mais incisivamente nos diversos setores do saber e da produção. Do ponto de vista não-pragmático, geramos leitores capazes de associar prazer espontâneo à razão, bem como interlocutores ativos de poesia, esta manifestação estética presente nas sociedades desde os grupos primitivos, e, por isso, julgamos, pertinente a toda humanidade - caso contrário, teria sido extinta.

O leitor geral esclarecido é indivíduo de formação que exige da poesia imediatamente uma metáfora, logo, sofre constantemente o risco de interpretação exagerada, ou "super-interpretação", como diz Umberto Eco (1995). Claro está que esse leitor tem uma atitude auto-motivada de aproximação ao poema, e que dele a leitura se efetiva não apenas em uma relação de prazer e cura, mas também em uma percepção da consistência estética, coesa entre forma e conteúdo. Muitas vezes, o leitor geral esclarecido não sabe se interpreta o texto considerando a intenção do autor, a intenção da obra ou sua intenção. Logo, não consegue inferir que elemento o levou à leitura que alcançou, daí sua recorrente incerteza em assegurar o valor de verdade desse alcance, o que o leva a hiperbolizar as metáforas ou a encontrá-las onde simplesmente elas não existem. 


\section{Revista Solta a Voz, v. 19, n. 1}

Sobre isso, Stierle (1979, p. 133-187) se preocupa em observar que a leitura ingênua tende inicialmente a um passo elementar de recepção, que é ter como ideal considerar que a um significante corresponda apenas um significado, implicando uma "redução". No entanto, observamos que, quanto ao leitor geral esclarecido, há uma adição excessiva de significados para um significante, e, muito embora sabendo que polissemicamente isso é muito possível, tal comportamento de um significante não se dá sempre. Assim, não existe apenas um significado, mas necessariamente não precisa haver tantos - bem como tantos não quer dizer qualquer um. Disso, o montante de significados suscitado pela recepção estética pode atordoar o leitor e, conseqüentemente, conduzi-lo a "forçar" uma interpretação. Sabemos que é difícil catalisar os significados contextuais devidos para cada significante por intermédio de uma sistematização, por isso é que a tomada de consciência sobre o histórico de formação do leitor é fundamentalmente pertinente. É preciso que saibamos que o leitor brasileiro traz consigo uma herança de leitura às pressas, resultado de uma conjuntura que foi se formando para garantir as benesses do elitismo, para resolver problemas imediatamente e sem prévia preparação, bem como para não reprimir atitudes imprudentes devido ao senso de amplo e aberto nepotismo que aqui se plantou desde a colonização.

O leitor geral esclarecido acredita que pode empreender aleatoriamente sua leitura, que o que há na poesia é passivo de toda e/ou qualquer interpretação. Não dizemos isso julgando que esse leitor tenha conhecimento do pós-estruturalismo, mas que ele ache que poesia é algo de tal modo subjetivo que é possível se dizer qualquer coisa sobre ela, algo como: tudo pode ser interpretaçáo se eu vejo assim. O que seria quase como considerar que um guarda-roupa e uma geladeira é uma mesma coisa. Quer dizer, seria considerar que não há instâncias sociais, coletivas, de geração do significado estético, e que o poema, por isso, seria absolutamente idiossincrático, seria expressão de um idioleto intraduzível. Se fosse assim, náo somente a leitura de poesia seria impossível quanto sua escritura seria completamente desnecessária, para náo dizer estúpida. Ademais, todo poeta, como todo leitor, por mais inconsciente de seu processo de composição (quanto àquele) e de sua recepção estética (quanto a este), são indivíduos sociais: são indivíduos autenticados e que autenticam dados significativos de convergência mútua, em cooperação fiduciária ou dialética, sistemática ou não. 
Seria dizer que, para aquele verso de Fernando Pessoa, esse leitor inferisse que o poeta estava à beira do suicídio. Efetivamente há uma angústia no dizer do sujeito daquele verso, embora não necessariamente na voz do poeta. Logo, a leitura aleatória não precisa ser ignorada, ainda que ela não apresente expressão crítica. Há certo sentido na inferência daquele leitor. Este artigo, por isso, não deseja a punição nem a extinção do leitor geral esclarecido. Deseja, com base na investigação que o resultou e na argumentação desenvolvida, promover um entendimento também crítico desse tipo de leitor e um alerta ou chamada de atençáo para que os modelos de leitura de poesia cada vez mais propostos pelo sistema de educação vigente não deixem de levar em conta o estado desse leitor, bem como sua conduta de recepção. Com base nisso, nossos resultados procuram mostrar que tipo de leitor a universidade e, às vezes, o Ensino Médio têm em mãos, para não atuar sobre ele como aquilo que esse leitor não é, seja para mais ou para menos de sua competência.

\section{REFERÊNCIAS}

ARAUJO, J. de S. Perfil do leitor colonial. Bahia: UESC, 1999.

CANDIDO, A. Literatura e sociedade: estudos de teoria e história literária. São Paulo: T. A. Queiroz, 2000.

ECO, U. Os limites da interpretação. Trad. de Pérola de Carvalho. São Paulo: Perspectiva, 1995.

HUSSERL, E. Husserl. Trad. de Željko Loparic e Andréa M. A. de Campos Loparic. São Paulo: Nova Cultural, 1996.

ISER, W. A interação do texto com o leitor. Trad. de Luiz Costa Lima. In: LIMA, L. C. A literatura e o leitor: textos de estética da recepção. São Paulo: Paz e Terra, 1979. p. 83-132.

- Teoria da recepção: reação a uma circunstância histórica. Trad. de Bluma Waddington Vilar e João Cezar de Castro Rocha. In: CASTRO ROCHA, J. C. de. Teoria da fiçãoo: indagaçóes sobre a obra de Wolfgang Iser. Rio de Janeiro: EDUERJ, 1999. p. 21-33.

JAUSS, H. R. A estética da recepção: colocação gerais. Trad. de Luiz Costa Lima. In: LIMA, L. C. A literatura e o leitor: textos de estética da recepção. São Paulo: Paz e Terra, 1979. p. 43-61. 
LAJOLO, M.; ZILBERMAN, R. Formação da leitura no Brasil. São Paulo: Ática, 1996.

PAZ, O. Os signos em rotação. Trad. de Sebastião Uchoa Leite. São Paulo: Perspectiva, 1976.

SODRÉ, N. W. História da literatura brasileira. 5. ed. Rio de Janeiro: Bertrand Brasil, 1995.

STIERLE, K. Que significa a recepção dos textos ficcionais? Trad. de Heidrun Krieger Olinto e Luiz Costa Lima. In: LIMA, L. C. A literatura e o leitor: textos de estética da recepção. São Paulo: Paz e Terra, 1979. p. 133-197.

VERÍSSIMO, J. Estudos de literatura brasileira. Belo Horizonte: Itatiaia; São Paulo: EDUSP, 1976.

Recebido em: 3 fev. 2008 Aceito em: 3 abr. 2008 